\title{
Xanthohumol-Supplemented Beer Modulates Angiogenesis and Inflammation in a Skin Wound Healing Model. Involvement of Local Adipocytes
}

\author{
Rita Negrão, ${ }^{1 *}$ Raquel Costa, ${ }^{1}$ Delfım Duarte, ${ }^{1}$ Tiago Taveira Gomes, ${ }^{1}$ Pedro Coelho,,${ }^{1,2}$ \\ João T. Guimarães, ${ }^{1,3}$ Luísa Guardão, ${ }^{4}$ Isabel Azevedo, ${ }^{1}$ and Raquel Soares ${ }^{1}$ \\ ${ }^{1}$ Department of Biochemistry (U38-FCT), Faculty of Medicine, University of Porto, Porto 4200-319, Portugal \\ ${ }^{2}$ Institute of Health Technologies, Gaia, Portugal \\ ${ }^{3}$ Department of Clinical Pathology, Hospital São João, Porto 4200-319, Portugal \\ ${ }^{4}$ Faculty of Medicine, University of Porto, Porto 4200-319, Portugal
}

\begin{abstract}
Angiogenesis and inflammation are two intermingled processes that play a role in wound healing. Nevertheless, whenever exacerbated, these processes result in nonhealing wounds. Xanthohumol (XN), a beer-derived polyphenol, inhibits these processes in many physiopathological situations. This study aimed at examining whether XN ingestion affects wound healing. Wistar rats drinking water, 5\% ethanol, stout beer (SB) or stout beer supplemented with $10 \mathrm{mg} / \mathrm{L} \mathrm{XN} \mathrm{(Suppl} \mathrm{SB)} \mathrm{for} 4$ weeks, were subjected to a $1.5 \mathrm{~cm}$ full skin-thickness longitudinal incision, and further maintained under the same beverage conditions for another week. No differences in beverage consumption or body weight were found throughout the study but food intake decreased in every group relative to controls. Consumption of Suppl SB resulted in decreased serum VEGF levels (18.42\%), $N$-acetylglucosaminidase activity (27.77\%), IL1 $\beta$ concentration (9.07\%), and NO released (77.06\%), accompanied by a reduced redox state as observed by increased GSH/GSSG ratio (to 198.80\%). Also, the number of blood vessels within the wound granulation tissue seems to reduce in animals drinking Suppl SB (23.08\%). Interestingly, SB and primarily Suppl SB showed a tendency to increase adipocyte number (to $194.26 \%$ and $156.68 \%$, respectively) and reduce adipocyte size ( $4.60 \%$ and $24.64 \%$, respectively) within the granuloma. Liver function and metabolism did not change among the animal groups as analyzed by plasma biochemical parameters, indicating no beverage toxicity. This study shows that XN intake in its natural beer context reduced inflammation, oxidative stress, and angiogenesis, ameliorating the wound healing process, suggesting that this polyphenol may exert beneficial effect as a nutritional supplement.
\end{abstract}

KEY WORDS: XANTHOHUMOL; BEER; WOUND HEALING; ANGIOGENESIS; INFLAMMATION; BLOOD VESSELS; POLYPHENOLS

A ngiogenesis, the formation of new capillaries from preexistent blood vessels, is a complex and highly regulated process that requires interaction between different types of cells, inflammatory cytokines, growth factors, and the extracellular matrix. Angiogenesis is a major contributor to tissue vascularization with primordial importance both in physiology and disease, as blood vessels are responsible for the transport of oxygen, nutrients, and other molecules to tissues and for removing metabolic waste [Costa et al., 2007].

Under physiological conditions, angiogenesis is highly regulated by the balance between pro- and anti-angiogenic factors, and in adulthood it occurs only in self-limited processes as for example in wound repair and tissue regeneration [Gollisch et al., 2009]. Pathological angiogenesis, inversely, may develop during years [Folkman, 2007] in conditions such as in cancer, cardiovascular disease, diabetes, obesity, and other pathologies associated with chronic inflammation.

In mammals, wound healing is a result of three overlapping processes: Hemostasis and inflammation, granulation tissue formation, re-epithelialization and remodelling, which enable wound closure and the restoration of a functional barrier [Tan et al., 2007]. Wound healing normally develops without 
complications, but the resolution of inflammation is critical. Indeed, several conditions like ageing, obesity, and many other disorders can compromise the normal resolution of the inflammation. This can result in chronic wound and ulcer development, leading to tissue damage [Pond, 2003]. Hence, reduction of the inflammatory phase is the aim of several therapeutic measures in order to resolve chronic wounds.

Macrophages are the most abundant cells 5 days upon wound injury, producing cytokines and growth factors required for wound healing, promoting collagen production, angiogenesis, and reepithelization with the formation of granulation tissue, the hallmark of an establishing healing response [Mahdavian Delavary et al., 2011]. Wound angiogenesis starts right at the beginning of the healing process and is amplified by inflammation and hypoxia, two driving forces for wound angiogenesis, leading to the production of VEGF, the most potent pro-angiogenic factor. VEGF, in turn, promotes blood vessel permeability enabling inflammatory factors and nutrients release necessary for the healing process, and also the survival and proliferation of endothelial cells (EC), guiding the newly formed blood vessels, that appear in the wound bed by 3-5 days after injury. EC, vascular smooth muscle cells (VSMC), macrophages, fibroblast, and extracellular matrix present in the wound area secrete several angiogenic factors, growth factors, and proteases that support the angiogenic process. At later stages of the healing process these regulators gradually return to normal level, which enhance new blood vessels stability [Chung et al., 2010]. When insufficient angiogenic stimulation occurs, it compromises the neovascularization and the normal regeneration of the wounded tissue, as new blood vessels are fundamental for the formation of the provisional matrix and for the delivering of oxygen and nutrients to growing tissue and removing metabolic waste products [Eming et al., 2007]. However, excessive pro-angiogenic stimulation also may result in poor perfusion as abnormal and no functional capillaries are formed. Both processes can result in chronic wound and ulcer development [Shoab et al., 1999].

Epidemiological and experimental evidence indicates that diets rich in plant-derived food protect from several pathologies, associated with inflammatory and angiogenic processes [Gerhauser, 2005; Oak et al., 2005; Soares and Azevedo, 2007]. These properties have mainly been attributed to the anti-oxidant and antiinflammatory effects of polyphenolic compounds [Biesalski, 2007; Stevenson and Hurst, 2007].

Beer consumption has increased worldwide, especially among the young generations. Beer contains more than 800 compounds, many of which are polyphenols that contribute to its flavour characteristics. Many of these polyphenols have been described as potent anti-oxidative, anti-inflammatory and anti-carcinogenic molecules, being, thus, possible contributors to the prevention of pathologies with high incidence and mortality rates in the western world [Stevens and Page, 2004; Gerhauser, 2005; Cho et al., 2008; Magalhaes et al., 2009].

Xanthohumol (XN) is a polyphenol almost exclusively present in hops, used in beer production. Due to the described health properties attributed to $\mathrm{XN}$, as anti-cancer, anti-invasive, anti-angiogenic, anti-inflammatory, and anti-oxidant [Gerhauser, 2005; Albini et al., 2006; Guerreiro et al., 2007; Monteiro et al., 2008; Negrao et al.,
2010], production of a polyphenol-enriched beer has been considered an interesting challenge to the brewing industry, particularly, because most beer production processing results in beers with a very low content in XN (0.002-1.2 mg/L) [Gerhauser, 2005].

In 2004, two new beverages were introduced in the German market, XAN Hefeweissbeer ${ }^{\circledR}$ and XAN Wellness ${ }^{\mathbb{R}}$, with elevated levels of XN $(1.4 \mathrm{mg} / \mathrm{L}$ and $4 \mathrm{mg} / \mathrm{L}$ respectively) [Winkelmann, 2004; Magalhaes et al., 2009]. Other following XN-enriched products are in development and trial, namely muesli bars, chocolate, yoghurt, bread, pastries, and biscuits (Xan products, TA-XAN AG, Company SCHULTZEPLUS, Germany) [Xan, 2011]. Nevertheless, the use of these food additives must be carefully taken, as very few studies about the safety of these additives were performed until now.

Previous work of our group demonstrated that different polyphenols present in beer exert different effects on angiogenesis and inflammation, resulting in differences in the wound healing process when these compounds were administered topically in the wound area [Negrao et al., 2010]. Namely, whereas 8-prenylnaringenin (8PN) stimulates angiogenesis, $\mathrm{XN}$ and isoxanthohumol (IXN) manifested anti-angiogenic and anti-inflammatory effects in identical conditions [Negrao et al., 2010].

In beer, these polyphenols are not isolated, being mixed with several other compounds in a complex matrix that may alter their final biological effect. Moreover, the administration route (e.g., ingestion vs. topical application) of polyphenols might lead to different actions in the body. The effects of the ingestion of XN were already studied by several groups [Albini et al., 2006; Monteiro et al., 2008; Bolca et al., 2010; Dorn et al., 2010]. However, the effects of beer and XN-supplemented beer ingestion on inflammation and angiogenesis were not clearly examined.

Given its dependence on angiogenesis and inflammation, wound healing is a good model for studying the effects of polyphenols in these two processes. In this work, we aimed to determine whether prolonged stout beer (SB) and XN supplemented stout beer $(10 \mathrm{mg} / \mathrm{L})$ intake could influence skin wound healing process, through angiogenesis and inflammation modulation. Furthermore, since adipose tissue is known to play a major role in oxidative stress and in the inflammatory process, we did also characterize the presence and morphology of adipocytes within skin damage tissue.

\section{MATERIALS AND METHODS}

\section{IN VIVO STUDIES}

All research animals were obtained, maintained, and used in experiments conducted according to accepted standards of humane animal care (Declaration of Helsinki, European Community guidelines (86/609/EEC) and Portuguese Act (129/92) for the use of experimental animals). A veterinary accompanied all steps involving animal care and manipulation. All the authors involved in animal studies in the present study received accreditation from the Portuguese Veterinarian Administration as a competent person for animal experimentation (investigator-coordinator). 


\section{BEER INFORMATION}

The beer used in this study was Superbock ${ }^{\circledR}$ SB (UNICER, Porto, Portugal), with the forward polyphenols composition: Polyphenols: $255 \pm 13 \mathrm{mg} / \mathrm{L}$; XN: Traces $(\mu \mathrm{M})$. The final concentration in the supplemented stout beer was $10 \mathrm{mg} / \mathrm{L}$. In order to ensure batch-tobatch consistency in XN levels in the baseline beer, we used SB from the same batch along all the experiment, assuring consistency regarding this point along the experiment.

\section{SKIN WOUND-HEALING ASSAY}

Wistar rats (Charles River, Wilmington, MA,), 6-week-old, were maintained under standard temperature and light conditions (20$22^{\circ} \mathrm{C}, 12$-h light/dark cycle). The animals were divided into four groups, of six animals each, that were subjected to different treatments: (1) water (control group, C), (2) 5\% ethanol solution in water (Et), (3) Superbock ${ }^{\circledR}$ SB, and (4) Superbock ${ }^{\circledR}$ SB supplemented with XN $10 \mathrm{mg} / \mathrm{L}$ (Suppl SB). The beverages were supplied to the rats ad libitum in dark bottles. All animals were maintained on standard ad libitum rodent chow. Body weight gain was monitored twice weekly. Beverages and animal pellet food were renewed and intake was assessed every 2-3 days. After 4 weeks of treatment, the animals were anesthetized, dorsal skin of the rat was shaved and cleaned. Full skin-thickness longitudinal incisions $(1.5 \mathrm{~cm})$ were created on the dorsal surface of the rat and the wound edges closed with surgical sutures at $0.5 \mathrm{~cm}$ intervals. The animals were kept in individual cages and continued beverage treatment for another week. Rats were examined daily for wound healing progression. After 7 days the animals were anesthetized and blood was drawn from the left ventricle to heparin-containing tubes for glutathione determination in plasma. Serum was also obtained for inflammatory factors and biochemical parameters evaluation. Wound tissue was removed, fixed in 10\% neutral-buffered formalin, paraffin-embedded, and sectioned for histological and immunohistochemical analyses.

\section{EVALUATION OF PLASMA BIOCHEMICAL PARAMETERS}

Plasma biochemical markers were measured in the Central Laboratory, Department of Clinical Pathology, Hospital São João, using conventional methods with an Olympus AU5400 ${ }^{\circledR}$ automated clinical chemistry analyzer. (Beckman-Coulter ${ }^{\circledR}$, Izasa, Porto, Portugal). Parameters evaluated included hepatic function markers such as aspartate aminotransferase (AST), alanine aminotransferase (ALT), and alkaline phosphatase (ALP) and markers of metabolic status including glucose, uric acid, triglycerides, total cholesterol, very low density lipoproteins cholesterol (VLDL), low density lipoproteins cholesterol (LDL), and high density lipoproteins cholesterol (HDL). LDL was calculated according to Friedewald's equation [Friedewald et al., 1972]: LDL-cholesterol = total cholesterol-HDL-cholesterol-(triglycerides/5). VLDL $=\mathrm{TRG} / 5$.

\section{GSH AND GSSG DETERMINATION IN RAT PLASMA}

Chromatographic detection of GSH/GSSG was performed as described in Glutathione (GSH/GSSG) HPLC Kit (Immundiagnostik, Germany) using a reverse-phase HPLC VWR-Hitachi Elite LaChrom System (VWR, Germany) and plasma samples. The system consisted of a pump model L-2130, an autosampler L-27200, a L-2300 Column
Oven, a BDS-Hypersil C18 analytical column $(10 \mathrm{~cm} \times 4.6 \mathrm{~mm}$ i.d.; 3- $\mu \mathrm{m}$ particle size) (Thermo Scientific) with no guard column and an FL detector model L-2485. After running the samples, the chromatograms were analyzed using Agilent EZChrom Elite 3.3.2 software (Agilent Technologies).

\section{IMMUNOHISTOCHEMISTRY ANALYSIS}

The microvessel density was evaluated in each formalin-fixed paraffin-embedded wounded tissue section. Immunostaining for von-Willebrand Factor (vWF) diluted 1:100 (Millipore, MA) was preceded by tissue slide digestion with pepsin freshly prepared solution $(0.5 \%$ in $5 \mathrm{mM} \mathrm{HCl})$ at $37^{\circ} \mathrm{C}$ for $20 \mathrm{~min}$. Negative controls were carried out by omission of the primary antibody in tissue sections expressing the marker. To ensure specific immunostaining by vWF, tissue slides of paraffin-embedded B16 mellanoma tumors were immunostained against vWF. Microvessel density was then evaluated in three tissue sections, for each animal, and normalised to the total area of the tissue section.

\section{ELISA ASSAYS}

VEGF was quantified in rats serum by ELISA (Rat VEGF immunoassay kit, R\&D Systems, Abingdon, UK) according to the manufacturer's instructions.

Interleukin (IL) $1 \beta$ was quantified in rats serum by ELISA (IL- $1 \beta-$ EASIA kit, BioSource, Nivelles, Belgium) according to the manufacturer's instructions.

\section{DETERMINATION OF N-ACETYLGLUCOSAMINIDASE ACTIVITY}

The $N$-acetylglucosaminidase (NAG) enzyme is present at high levels in activated macrophages. Inflammation can be evaluated by measuring the levels of the lysosomal NAG enzyme in the serum. Serum was incubated for $10 \mathrm{~min}$ at $37^{\circ} \mathrm{C}$ with $100 \mu \mathrm{l}$ of $p$ nitrophenyl- $N$-acetyl-beta-D-glucosaminide solution in a 96 -well plate. The reaction was stopped by the addition of $0.2 \mathrm{M}$ glycine buffer ( $\mathrm{pH}$ 10.6) and the subtrate hydrolysis was measured at $405 \mathrm{~nm}$.

\section{NO DETERMINATION}

NO level was determined as the concentration of nitrate plus nitrite in the serum by colorimetric assay. Serum was incubated with equal volume of Griess Reagent in a 96-well microtiter plate, for $15 \mathrm{~min}$ at room temperature. Measurement was performed in a spectrophotometer plate reader at $550 \mathrm{~nm}$. Data were expressed as NO concentration $(\mu \mathrm{M})$.

\section{ADIPOCYTE SIZE AND NUMBER}

Hematoxylin- and eosin-stained $5 \mu \mathrm{m}$-thick paraffın-embedded sections of wound healing areas were observed in a blind study and adipocyte size measurement and quantification were performed as described. Briefly, microscopic pictures covering the whole analyzed area were taken. Using Adobe Photoshop CS5, a compound image was created with all the acquired pictures. All adipocytes were then outlined and adipocyte number and area measurements were computed automatically. 


\section{STATISTICAL ANALYSES}

Every assay was performed at least in three independent experiments. Quantifications are expressed as mean \pm SEM and/or as percentage of control, which was considered to be $100 \%$. Statistical significance of difference between various groups was evaluated by analysis of variance (ANOVA) followed by the Bonferroni test. A difference between experimental groups was considered significant with a confidence interval of 95\%, whenever $P \leq 0.05$.

\section{RESULTS}

FOOD AND BEVERAGE INTAKE AND BODY WEIGHT MEASUREMENT Every group ingested the same amount of beverage per day. However, the higher caloric intake among the groups drinking 5\% ethanol-containing beverages was compensated by the ingestion of significantly smaller amounts of food by Et (7.23 $\pm 0.23 \mathrm{~g} /$ day/100 g body weight), SB (6.65 $\pm 0.25 \mathrm{~g} /$ day/100 g body weight), and Suppl SB $(6.35 \pm 0.24 \mathrm{~g} / \mathrm{day} / 100 \mathrm{~g}$ body weight $)$ treated animals when compared to control group ( $8.30 \pm 0.24 \mathrm{~g} /$ day/ $100 \mathrm{~g}$ body weight) (Fig. 1A,B).

We next examined whether the different treatments exerted any influence on rat body weight. Body weight gradually increased in every studied group throughout the 5 weeks of treatment, exhibiting an identical rate of weight gain for each group (Fig. 1C). Accordingly, at the end of experiment ( 5 weeks), body weight did not differ between the four groups of treated animals (Fig. 1C).

\section{BIOCHEMICAL PARAMETERS AND HEPATIC ENZYME ACTIVITY EVALUATION}

We then analyzed hepatic and biochemical serum parameters as indicators of liver damage and function, and of metabolism, after different beverage treatments. The hepatic enzyme activities of ALT, AST, gamma-glutamyltransferase (GGT), and ALP exhibited similar values among the four different treated animal groups, indicating that there was no hepatic toxicity with the ingested doses of these beverages, during 5 weeks (Table I).

In order to evaluate the metabolic profile of the studied animals, we also quantified biochemical parameters including glucose, uric acid, triglycerides, cholesterol, VLDL, LDL, and HDL. Careful analysis of Table I seemed to indicate a similar decrease in plasma triglycerides in both SB and Suppl SB, two tested beers with very different quantities of bioactive components, comparatively to $\mathrm{C}$ and Et groups. However, statistical analysis of the results did not confirm that difference. No significant alterations were observed for all other biochemical parameters, confurming a normal hepatic cell function regarding carbohydrate and lipid metabolism (Table I).
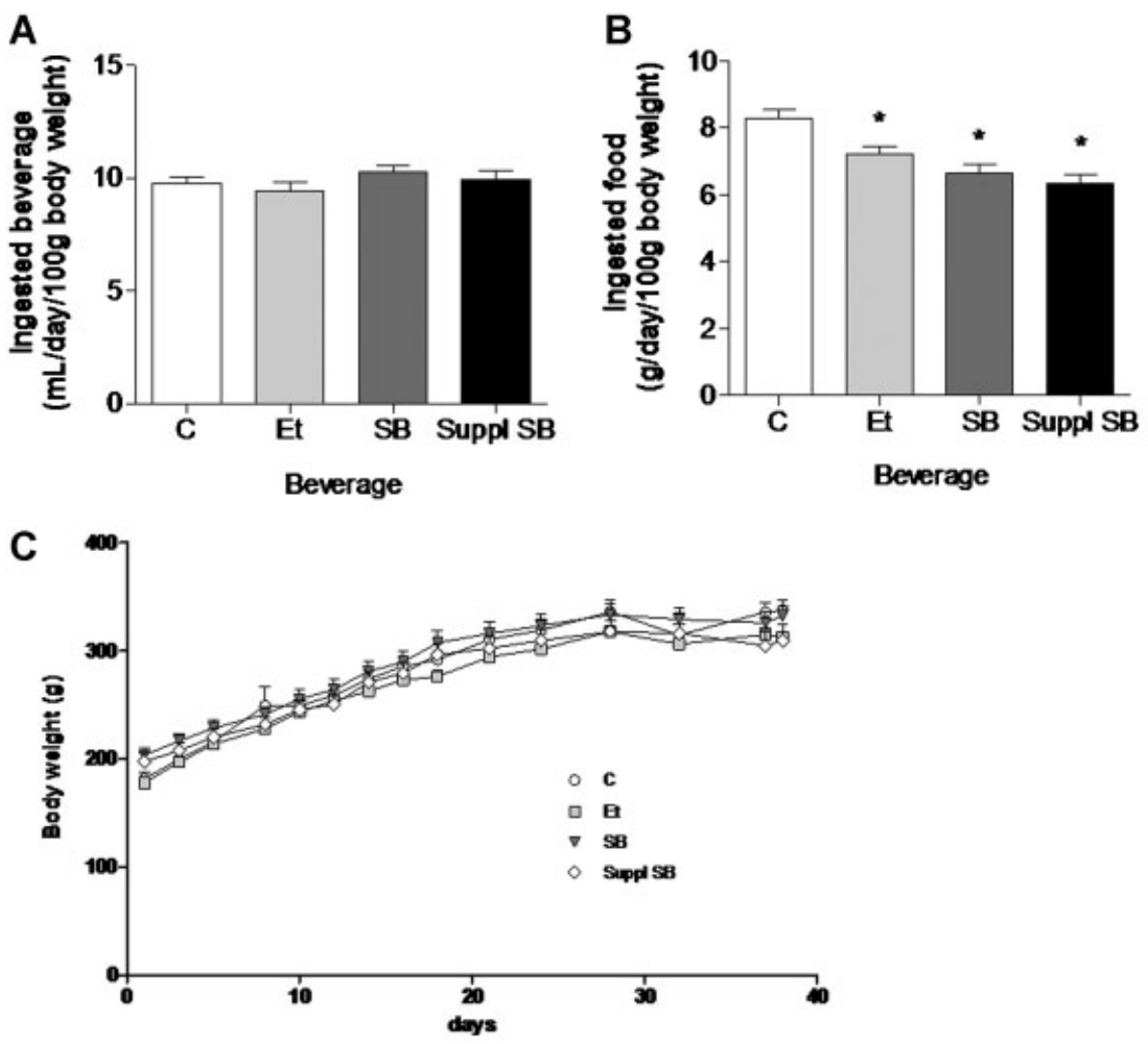

Fig. 1. Mean values for (A) beverage and (B) food intake by Wistar rats subjected to distinct treatments during 5 weeks. $C$ : Rat body weight measurement during the five-week treatment with the different beverages intake. C, control group; Et, 5\% ethanol solution in water; SB, Superbock ${ }^{\mathbb{B}}$ stout beer; Suppl SB, xanthohumol-supplemented Superbock ${ }^{\mathbb{R}}$ stout beer. Results are presented as means $\pm \mathrm{SEM}(\mathrm{n}=7){ }^{*} \boldsymbol{P} \leq 0.05$ versus $\mathrm{C}$. 
TABLE I. Analysis of Plasma Biochemical Markers in Wistar Rats After 5-Week Consumption of Water (C, Control), 5\% Ethanol (Et), Stout Beer (SB), or XN-Supplemented Stout Beer (Suppl SB)

\begin{tabular}{|c|c|c|c|c|}
\hline & $\mathrm{C}$ & Et & SB & Suppl SB \\
\hline AST (U/L) & $103.4 \pm 13.04$ & $80.3 \pm 8.78$ & $69.0 \pm 4.28$ & $75.0 \pm 7.0$ \\
\hline $\operatorname{ALT}(\mathrm{U} / \mathrm{L})$ & $26.0 \pm 0.7$ & $26.0 \pm 1.79$ & $23.8 \pm 1.9$ & $21.67 \pm 2.36$ \\
\hline AST/ALT & $3.8 \pm 0.7$ & $3.2 \pm 0.3$ & $3.1 \pm 0.4$ & $3.1 \pm 0.2$ \\
\hline $\operatorname{ALP}(\mathrm{U} / \mathrm{L})$ & $116.7 \pm 9.7$ & $91.3 \pm 7.1$ & $144.8 \pm 13.7$ & $108.2 \pm 14 . C$ \\
\hline GGT(U/L) & $2.0 \pm 0.2$ & $1.3 \pm 0.3$ & $2.0 \pm 0.2$ & $2.8 \pm 0.2$ \\
\hline Glucose (mg/dl) & $147.0 \pm 7.0$ & $189.0 \pm 36.0$ & $135.0 \pm 6.0$ & $160.0 \pm 9.0$ \\
\hline Uric acid (mg/dl) & $1.09 \pm 0.06$ & $0.91 \pm 0.12$ & $0.73 \pm 0.07$ & $0.74 \pm 0.14$ \\
\hline Triglycerides (mg/dL) & $90.0 \pm 7.0$ & $87.0 \pm 8.0$ & $64.0 \pm 8.0$ & $68.0 \pm 9.0$ \\
\hline Cholesterol (mg/dl) & $43.0 \pm 2.0$ & $41.0 \pm 2.0$ & $41.0 \pm 2.0$ & $47.0 \pm 3.0$ \\
\hline VLDL (mg/dl) & $23.0 \pm 3.0$ & $22.0 \pm 3.0$ & $18.0 \pm 4.0$ & $18.0 \pm 4.0$ \\
\hline LDL (mg/dl) & $12.0 \pm 1.0$ & $11.0 \pm 1.0$ & $11.0 \pm 1.0$ & $12.0 \pm 1.0$ \\
\hline HDL (mg/dl) & $23.0 \pm 1.0$ & $26.0 \pm 2.0$ & $23.0 \pm 1.026 .0$ & $25.0 \pm 2.0$ \\
\hline
\end{tabular}

Evaluated parameters included hepatic function markers, such as aspartate aminotransferase (AST), alanine aminotransferase (ALT), gamma-glutamyltransferase (GGT), and alkaline phosphatase (ALP) activities and markers of metabolic status including glucose, uric acid, triglycerides, total cholesterol, very low density lipoprotein cholesterol (VLDL), low density lipoprotein cholesterol (LDL), and high density lipoprotein cholesterol (HDL). Results are presented as means \pm SEM of independent experiments $(4 \leq n \leq 6)$.

\section{SB AND SUPPL SB BEVERAGE TREATMENTS IMPROVED ANTI-OXIDANT DEFENSES}

To characterize the general redox state after 5 weeks of treatment with the study beverages, we evaluated endogenous anti-oxidant defenses. As reduced glutathione (GSH) plays a critical role in the maintenance of the thiol redox status in cells, the determination of GSH or the GSH/oxidized glutathione (GSSG) ratio is a useful marker of oxidative stress. The effect of treatments on plasma glutathione levels is illustrated in Figure 2. Chronic consumption of both SB and Suppl SB resulted in an increase of plasma GSH levels (to $124.79 \pm 7.60 \%$ and $152.69 \pm 11.41 \%$, respectively) as compared to $C(100.00 \pm 15.04 \%)$ and Et $(97.21 \pm 18.37 \%)$ groups. Nevertheless, a statistically significant difference was only observed in the group that ingested Suppl SB. No differences were found between C and Et groups. In contrast, all the beverages significantly reduced serum GSSG levels to $68.33 \pm 11.12 \%$ (Et), $51.84 \pm 3.88 \%$ (SB), and $56.47 \pm 4.85 \%$ (Suppl SB) relatively to control group. Accordingly, the GSH/GSSG ratio in rat plasma increased slightly in Et treated animals (to $134.31 \pm 16.65 \%$ ), and significantly in SB (to $163.82 \pm 10.02 \%$ ) and Suppl SB (to $198.80 \pm 8.44 \%$ ) groups. This latter showed a significant increase in comparison both to $\mathrm{C}$ and $\mathrm{Et}$ rat groups (Fig. 2). Altogether, these findings indicate that $\mathrm{XN}$ -

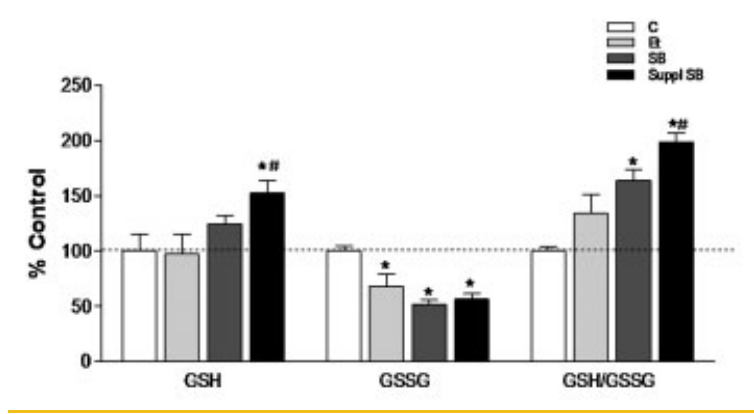

Fig. 2. Chromatographic detection of GSH and GSSG in plasma of animals treated with C, water control group; Et, 5\% ethanol solution in water; SB, Superbock ${ }^{\mathbb{R}}$ stout beer; Suppl SB, xanthohumol-supplemented Superbock ${ }^{\mathbb{B}}$ stout beer. Results are means \pm SEM $(4 \leq n \leq 6)$ and are expressed as percentage of control. ${ }^{*} P \leq 0.05$ versus $C ; \# P \leq 0.05$ versus Et. enriched beer is able to increase systemic anti-oxidant defences in skin-injured Wistar rats.

\section{POLYPHENOL-RICH BEVERAGES DIMINISHED LOCAL AND SYSTEMIC ANGIOGENESIS AND INFLAMMATORY MARKERS}

Skin wound healing is a process involving the formation of new extracellular matrix, cell infiltration, and tissue remodeling. Two fundamental physiological phenomena are deeply implicated in this process: Inflammation and angiogenesis. On day 7 post-injury, macroscopic evaluation of the external surface of the healing area, in the dorsal skin of the animals, showed no differences in the wound area after a 7-day treatment with any beverage, comparatively to the control group. However, the corresponding histological sections revealed that the granulation tissue of the incision area of animals treated with Suppl SB seemed more homogeneous, thinner, and with less inflammatory infiltration than that of control animals (Fig. 3C,D).

The ingestion of 5\% ethanol was accompanied by a slight increase in the number of blood vessels in the wounded area $(21.10 \pm$ 2.19 vessels $/ \mathrm{mm}^{2}$ ) in comparison to controls (16.68 \pm 1.51 vessels/ $\left.\mathrm{mm}^{2}\right)$. Inversely, SB $\left(15.88 \pm 1.94\right.$ vessels $\left./ \mathrm{mm}^{2}\right)$ and Suppl SB $\left(12.83 \pm 1.00\right.$ vessels $\left./ \mathrm{mm}^{2}\right)$ ingestion led to a tendency to microvessel density reduction (Fig. 3A,B) surrounding the wounded area, although none of these observed effects reached statistical significance relative to controls. Interestingly, consumption of $\mathrm{XN}$-enriched beer resulted in a significant decrease in the number of blood vessels within the wounds when compared to ethanol treated mice ( $\# \underline{P}<0.05$ vs. Et).

An identical profile was found for serum VEGF quantification (Fig. 4A). Ingestion of 5\% ethanol increased VEGF in the serum $(60.74 \pm 2.94 \mathrm{pg} / \mathrm{ml})$ comparatively to control group $(52.43 \pm$ $0.80 \mathrm{pg} / \mathrm{ml})$ ( $P \leq 0.05$ vs. C). In contrast, consumption of SB and Suppl SB significantly reduced VEGF levels in rats serum $(47.51 \pm 1.71 \mathrm{pg} / \mathrm{ml}$ and $42.77 \pm 0.30 \mathrm{pg} / \mathrm{ml}$, respectively). Remarkably, VEGF was significantly decreased in Suppl SB as compared to C, Et, and SB.

The activity of pro-inflammatory markers in rats serum followed the same outline. NAG activity was higher in Et group $(150.18 \pm 8.32 \%)$, revealing an increased systemic inflammatory 

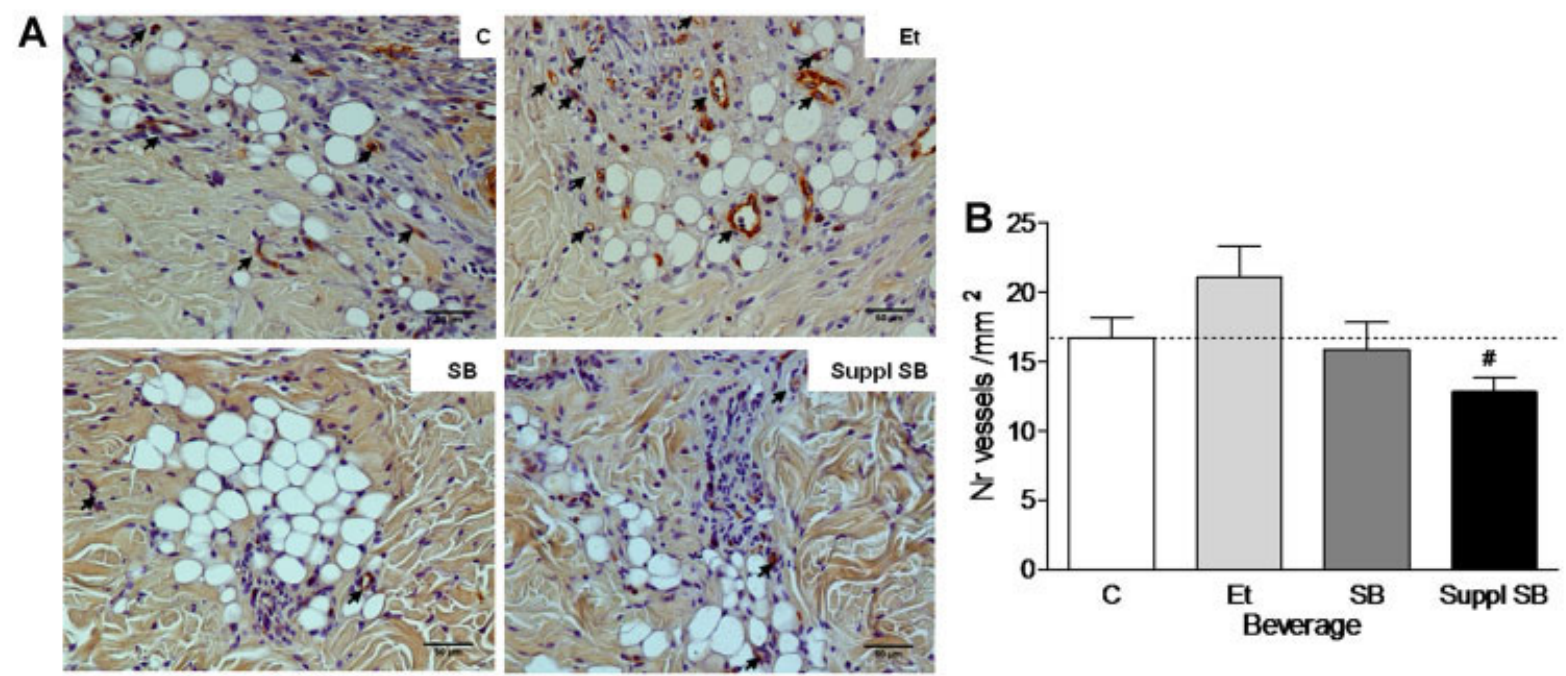

C

D
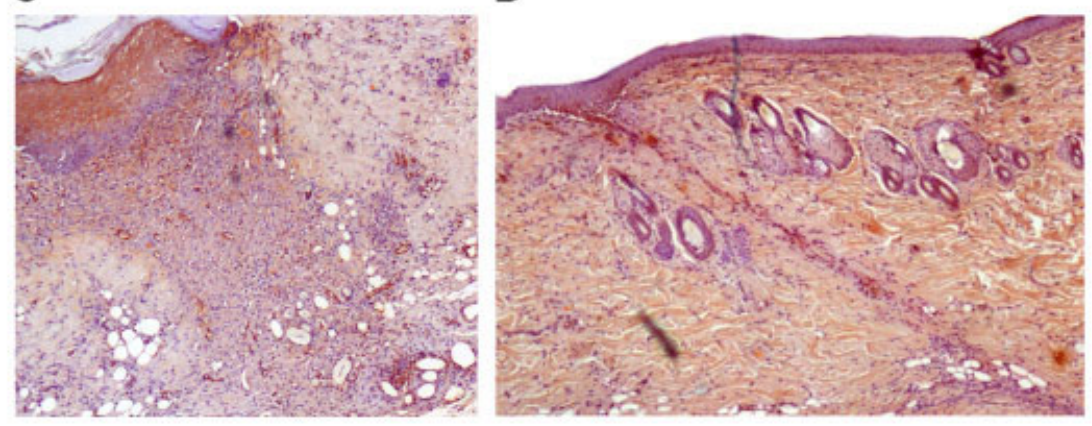

Fig. 3. Skin wound-healing assay. After 4 weeks of beverage supplied to the rats ad libitum in dark bottles, longitudinal incisions were created on the dorsal surface of the rats and beverages were supplied for more 7 days. Water control group (C); $5 \%$ ethanol solution in water (Et); Superbock ${ }^{\mathbb{B}}$ stout beer (SB); and xanthohumol supplemented stout beer (Suppl SB). Then, wound tissue was collected for angiogenesis evaluation. A, wound tissue section micrographs, using anti-von-Willebrand Factor (vWF) for evaluation of blood vessels (immunostaining, magnification: $200 \times$ ). Black arrows indicate blood vessels. B, quantification of blood vessels present in three tissue sections, for each animal, and normalized to the total area of the tissue section. Results are presented as means \pm SEM $(4 \leq n \leq 6)$, \#P<0.05 vs. Et. C: Control (C) and (D) Suppl SB, immuno-stained micrographs of wound tissue sections, highlighting different thickness of granulation tissue fulfilling the incision with different treatments (magnification: $40 \times$ ).

status significantly different from control group (100.00 $\pm 16.94 \%)$ and diminished to values similar to those obtained with control groups in rats that ingested SB (106.04 $\pm 10.04 \%)$, decreasing even more for Suppl SB (to $72.23 \pm 8.62 \%$ ) (Fig. 4B). These latter findings were corroborated by an identical profile obtained for IL1 $\beta$ determination (Fig. 4C). Et increased IL1 $\beta$ levels in serum to $138.13 \pm 2.00 \%$ and Suppl SB diminished its levels to $90.93 \pm 1.53 \%$.

NO determinations resulted in a highly significant NO reduction for both SB and Suppl SB treatments to $35.23 \pm 1.84 \%$ and to $22.94 \pm 2.68 \%$, respectively. Serum NO amount in Et group $(106.11 \pm 7.55 \%)$ was similar to that observed in C group $(100.00 \pm 13.12 \%)$.

\section{SB AND SUPPL SB TEND TO INCREASE ADIPOCYTE NUMBER AND DIMINISH ITS SIZE IN THE WOUND SITE AREA}

A closer observation of the skin damaged tissue revealed that the presence of adipocytes within granulation tissue was distinct among the different groups (Fig. 3A). These findings, together with the recent established role of adipocytes in inflammation, prompted us to determine the size and number of these cells in wound healing process after SB or Suppl SB consumption.

Determination of adipocyte area revealed a tendency to a progressive decrease of the adipocyte size in SB $\left(476.0 \pm 21.50 \mu \mathrm{m}^{2}\right)$ and Suppl SB $\left(376.0 \pm 45.88 \mu \mathrm{m}^{2}\right)$ when compared to $\mathrm{C}$ $\left(499.0 \pm 64.01 \mu \mathrm{m}^{2}\right)$ and to Et $\left(515.5 \pm 23.55 \mu \mathrm{m}^{2}\right)$ treated animals. This reduction in adipocyte size seemed higher for Suppl SB, although this difference did not reach statistical significance (Fig. 5A). Histological analysis also revealed that the number of adipocytes in the wound-healing area tended to increase in SB (76.25 \pm 18.12 adipocyte $\left./ \mathrm{mm}^{2}\right)$ and Suppl SB $(61.50 \pm 11.50$ adiadipocyte $\left./ \mathrm{mm}^{2}\right)$ when compared to C $(39.25 \pm 6.25$ adipocyte / $\left.\mathrm{mm}^{2}\right)$ and Et treated $\left(37.43 \pm 4.95\right.$ adipocyte $\left./ \mathrm{mm}^{2}\right)$ groups, although again not reaching statistical significance (Fig. 5B).

\section{DISCUSSION}

Wound healing is a physiological process necessary for repair and regeneration of injured skin tissue. This process greatly depends on the crosstalk between inflammation, oxidative stress, and 

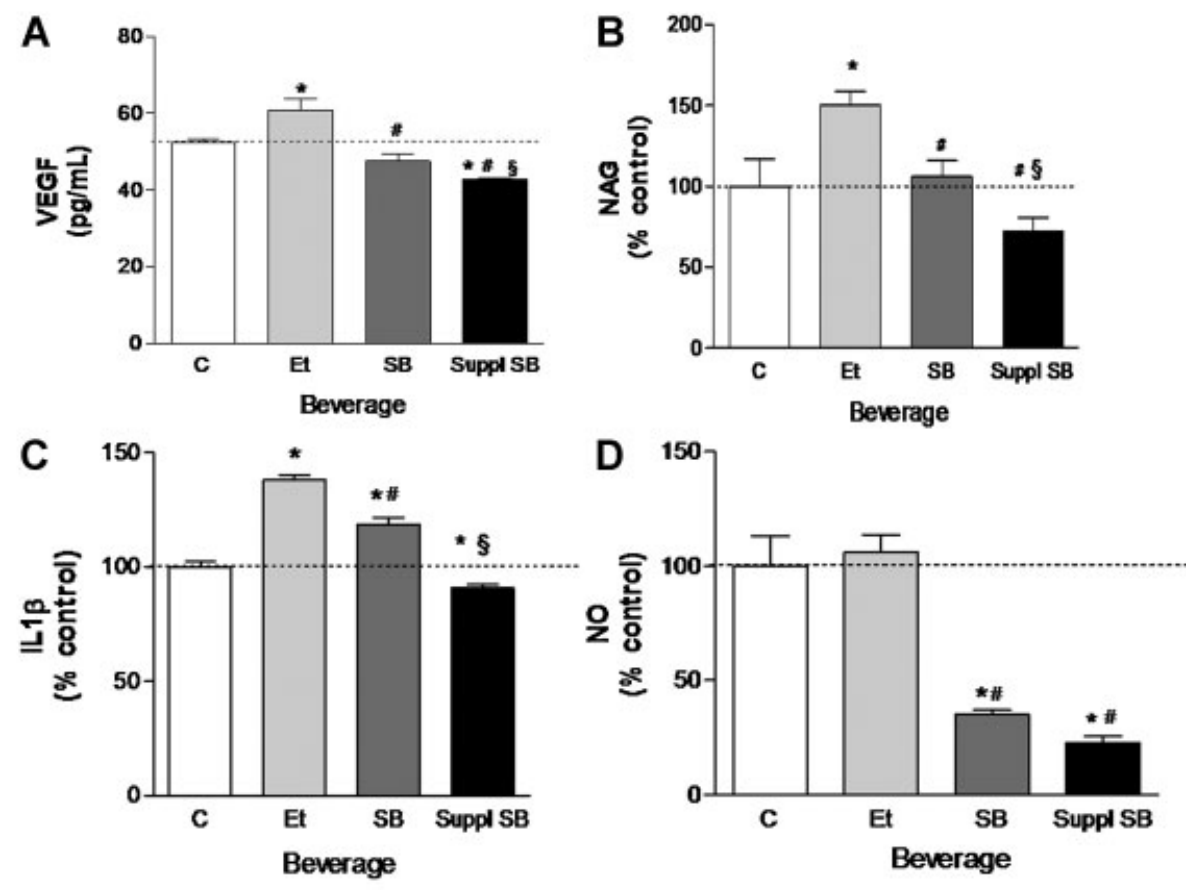

\begin{abstract}
Fig. 4. Evaluation of angiogenesis and inflammatory markers in skin injured Wistar rats, after 4 weeks of beverage supplied to the rats ad libitum in dark bottles. $\mathrm{C}$, Water control group; Et, 5\% ethanol solution in water; SB, Superbock ${ }^{\mathbb{B}}$ stout beer; Suppl SB, xanthohumol-supplemented Superbock ${ }^{\mathbb{B}}$ stout beer. Longitudinal incisions were created on the dorsal surface of the rats and beverages were supplied for more 7 days. Blood was then collected for systemic angiogenesis and inflammation markers evaluation. $A$ : VEGF levels; (B) N-acetylglucosaminidase (NAG) activity; (C) IL1 $\beta$ levels; (D) NO levels. Results are presented as means \pm SEM (4 $\leq n \leq 6)$ and are expressed as percentage of control. ${ }^{*} P \leq 0.05$ versus $C ; \# P \leq 0.05$ versus Et; $\$ P \leq 0.05$ versus $\mathrm{SB}$.
\end{abstract}

angiogenesis [Soares, 2009]. Discovering novel promoters of optimal wound healing, as well as identifying possible nutritional intervention factors able to ameliorate the process becomes a mandatory issue, as compromise of the normal resolution of the inflammation and angiogenic processes, can result in chronic wound and ulcer development, leading to tissue damage.

The current study demonstrates that consumption of SB and particularly XN-supplemented stout beer (Suppl SB) seemed to improve wound healing resolution. We were able to show that Suppl SB wound bed seemed better re-epithelizated than the correspondent area in control group. Also, the number of blood vessels tends to decrease in rat wounds consuming Suppl SB, and this was accompanied by reduced levels of VEGF, oxidative stress, and inflammatory markers in blood serum. Altogether, these findings led us to assume that wound healing enhancement was due to a reduction in the inflammatory phase and consequently a more controlled angiogenic process.

Inflammatory cells appear very rapidly in a wound after injury and remain until 3-5 days, as reported by Kagawa and collaborators [Kagawa et al., 2009]. Accordingly, our results demonstrate that at day 7, SB and Suppl SB diminished the levels of inflammatory markers, namely IL-1 $\beta$, NAG activity, and NO. On contrary, at this time point, rats treated with Et exhibited increased systemic IL-1 $\beta$ and NAG activity, indicating the occurrence of macrophage activation.

Although with different etiology, most chronic wounds result from a deficient progression from the inflammatory to the granulation tissue formation. Abnormal macrophage infiltration and prolonged inflammation has been described in chronic and diabetic wounds [Loots et al., 1998; Rodero and Khosrotehrani, 2010]. So, the decrease in systemic inflammatory markers observed after SB and Suppl SB consumption may result in a better controlled inflammatory response, in the presence of polyphenols, which were even able to overcome the pro-inflammatory profile induced by the ethanol present in the tested beverages. A better regulation of the inflammatory phase could improve wounds healing characterized by an excessive inflammatory profile, through a better transition to the granulation phase. Patients with chronic venous ulcers have sustained higher production of VEGF in the wound, which explains the vascular permeability and increased transudation of the wound area, resulting in disruptive new vessels [Shoab et al., 1999]. The decreased VEGF levels, observed for Suppl SB treatment, together with improved inflammatory conditions, could promote the stabilization of the new blood vessels, resulting in a better perfusion of the wounded tissue, helping the resolution of this kind of chronic wounds. Diabetic wounds also exhibit delayed wound closure but in contrast, VEGF levels are lower, leading to poor angiogenesis. Qiao demonstrated that the number of EC in diabetic rat wounds is identical to that found in nondiabetic wounds, but they were unable to form functional vessels [Qiao et al., 2011]. Then, chronic wounds may differ accordingly to established pathologies. In some situations wound resolution would improve by diminishing angiogenic stimulation and in others by enhancing angiogenesis. 

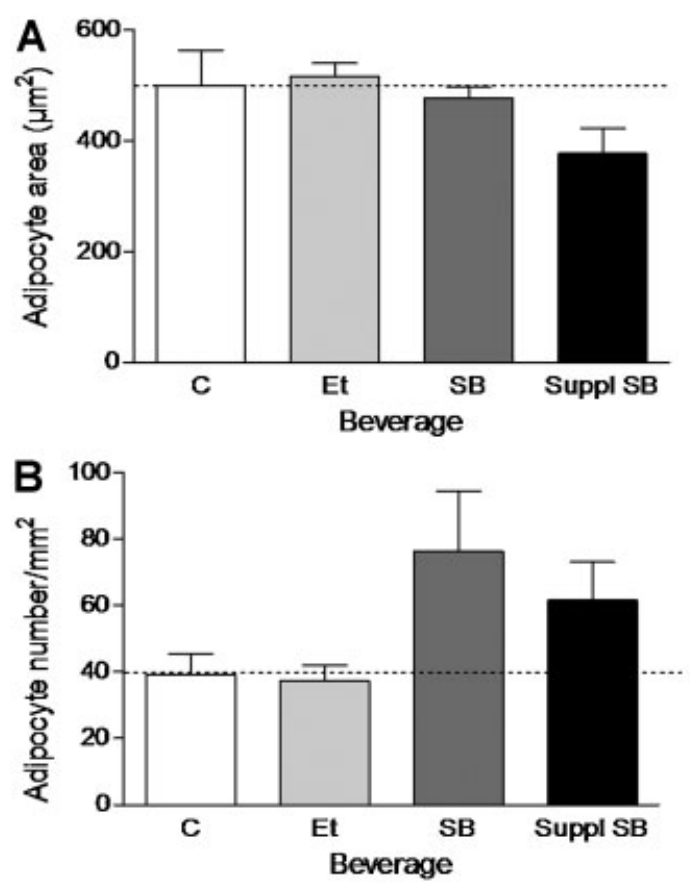

Fig. 5. Adipocytes (A) size and (B) number observed under identity occultation in hematoxylin \& eosin (HE)-stained $5 \mu \mathrm{m}$-thick sections of skin wound healing area. $C$, control (water-drinking animals); Et, $5 \%$ ethanol solution in water; SB, Superbock ${ }^{\mathbb{R}}$ stout beer; Suppl SB, xanthohumol-supplemented Superbock ${ }^{\circledR}$ stout beer. Results are represented as means $\pm \operatorname{SEM}(4 \leq n \leq 6)$.

But not always an increase in angiogenesis is related to better perfusion of the wound area, as the new blood vessels need to have conditions to stabilize and function properly. As polyphenols, and more specifically XN, can act simultaneously in different molecular targets, involving both inflammation and angiogenesis, the resulting regulation of the interplay of these two processes can improve chronic and also normal wound healing resolution, as XN can finely modulate inflammation and angiogenesis, accordingly to the progression of wound environment.

The study was accomplished by providing beverages to rats during a total of 5 weeks, 4 weeks before performing the skin incisions and 1 after the incisions were done. This study design allowed us to better understand the potential health benefits of regular ingestion of polyphenol-rich beverages in their natural context and its potential preventive effect. Beer ingestion in our rat experiment corresponded to a moderate alcohol intake by humans, approximately to $0.9 \mathrm{~L}$ beer/day by a man of $60 \mathrm{~kg}$ [Reagan-Shaw et al., 2008]. The establishment of the chronic treatment in our experimental model gains particular relevance, considering that polyphenols accumulate in macrophages and other cells or tissues at relatively high concentrations [Kawai et al., 2008; Bolca et al., 2010], when comparing with plasma concentrations. It has also been suggested that polyphenols may exert biological effects through specific targets at much lower concentrations than those initially suspected. Indeed, low amounts of polyphenols may specifically interact with proteins or particular lipid bilayer components [Fraga et al., 2010] and this may also explain the observed in vivo effects despite the low bioavailability described for polyphenols.

In agreement with the literature, biochemical analyses of serum parameters revealed no significant differences between the groups treated with the different beverages, indicating a normal liver function and lipid and carbohydrate metabolism in treated animals. In line with our results, Dorn et al. [2010] described no adverse toxic effects of $1,000 \mathrm{mg} \mathrm{XN} / \mathrm{kg}$ body weight/day after oral ingestion in mice during 3 weeks. Other authors also observed no toxic effects with $100 \mu \mathrm{M}$ ingestion of XN [Monteiro et al., 2008]. XN has been described to alter lipid and carbohydrate metabolism, lowering levels of plasma glucose and triglycerides [Gasowski et al., 2004; Nozawa, 2005]. Although our results seemed to indicate a decrease in serum triglycerides in SB and Suppl SB, these results were not statistically different.

During the last decades, the beneficial role of polyphenols was almost exclusively attributed to their anti-oxidant capacity, related to the reduction of excessive production of reactive oxygen species, which would induce an oxidative stress state [Holst and Williamson, 2008]. Nowadays, it is believed that polyphenol mechanisms of action in vivo are much more complex and these compounds may even exert their effect by acting as pro-oxidants, at low concentrations, preparing cells to respond in more severe stress conditions [Tosetti et al., 2009]. Ethanol by itself diminished GSSG levels in serum but did not change GSH, resulting in a slight increase, although not statistically significant, of the GSH/GSSG ratio. Other authors suggest that moderate ethanol consumption can stimulate anti-oxidative defences protecting from oxidation produced by ethanol consumption. These authors reported an increase in glutathione reductase activity, necessary for the utilization of GSSG formed and regenerate the GSH, maintaining the GSH/GSSG ratio, accordingly to our results [Assuncao et al., 2009]. Other authors [Roig et al., 1999] observed similar effects in what concern GSH/GSSH ratios for ethanol. Our results demonstrated that $\mathrm{XN}$, in the presence of ethanol, substantially and significantly, increased GSH and diminished GSSG, resulting in a great improvement of GSH/GSSG ratio, suggesting not only an increase of anti-oxidant-defences but probably, a decrease in oxidant levels due to its inherent anti-oxidant capacity. We found that consumption of both SB and Suppl SB resulted in a significantly higher GSH/GSSG ratio in serum than the one obtained in control rats. Although not statistically significant the increase in GSH and GSH/GSSG seems to be consistently higher for Suppl SB comparatively with SB. Also, the difference of GSH between C or Et groups and Suppl SB was statistically significant but not when comparing C or Et with SB. In what concerns GSSG levels, both SB and Suppl SB effects were similar.

GSH is used to eliminate peroxides, maintain thiol/disulfide redox state of proteins, and maintain the redox state of ascorbate and (indirectly) vitamin $\mathrm{E}$ in their reduced and functional forms [Jones, 2006]. The apparently higher level of GSH after Suppl SB ingestion may be due to the higher levels of $\mathrm{XN}$, a known anti-oxidant polyphenol. This anti-oxidative capacity may be considered one of the potential contributors to wound healing resolution by $\mathrm{XN}$. Altavilla et al. [2001] proposed that diabetes is associated with elevated oxidative stress and inflammation, and that by reducing 
lipid peroxidation in wounds of diabetic mice, it would be possible to reverse edema and stimulate the healing process. This would correspond to the reversion of the negative effects of diabetes in wound healing. In a recent paper [Strathmann et al., 2010], however, $\mathrm{XN}$ is described as a rapid inducer of thiol depletion and a producer of superoxide radical at mitochondria, inducing disruption of mitochondrial integrity and apoptosis in cancer cells, but at much higher concentrations $(1.6-50 \mu \mathrm{M})$ than those obtained in vivo, as far as it has been described [Gerhauser, 2005].

Several studies have tried to evaluate the effect of ethanol consumption on angiogenesis. Morrow et al. [2008] demonstrated that moderate consumption of alcohol enhances endothelial proangiogenic activity in vitro through a novel Notch-angiopoeitin-1/ Tie2 signaling pathway. Tan et al. [2007] reported that moderate ethanol consumption ( $1 \%$ ethanol), associated with alcoholic beverage consumption in humans, equivalent to two drinks per day induced the expression of VEGF and angiogenesis in mice melanoma. Other groups did also report an increase in angiogenesis in different models both in vivo and in vitro [Gu et al., 2005; Bora et al., 2006] in response to ethanol ingestion. On the other hand, Radek et al. [2008] found that acute ethanol exposure impairs angiogenesis probably by changes in the response to VEGF and hypoxia by endothelial cells, in a wound healing model. Although not statistically significant, our results suggest that chronic ingestion of 5\% ethanol increases the number of vessels formed in the wound area, after 7 days of the injury, when compared to control (water ingestion) as already described by other groups (see above). Strikingly, SB and Suppl SB reversed ethanol effect. Consistently, we observed an increase of systemic inflammatory markers as well as VEGF upon consumption of ethanol, which was again reversed by SB and Suppl SB.

In recent years the way we see adipose tissue has changed from a simple lipid and energy storage to a multifunctional complex organ with autocrine, paracrine, and endocrine functions. A remarkable finding of the present work that corroborates this idea was the appearance of distinct adipose tissue patterns within the granuloma tissue upon different treatments. SB and particularly Suppl SB consumption led to decreased adipocyte size and increased adipocyte number in wounded skin corresponding to subcutaneous adipose tissue. The precise function of these adipocytes in the granulation tissue area remains unknown. Interestingly, adipocyte hypertrophy has been associated with inflammatory dysfunction [Monteiro et al., 2006; Monteiro, 2009]. It has been described that adipose tissue from obese rats impaired wound contraction associated with an increased inflammatory phase [Nascimento and Costa, 2006]. Although necessary for wounds to heal, inflammatory cytokines are present in excess in nonhealing wounds. Adipocytes are known to communicate with endothelial and inflammatory cells in a paracrine manner, through the production of several cytokines that modulate blood vessel remodeling and assembly, thus promoting the healing process. Therefore, the fact that Suppl SB results in reduced adipocyte size may imply a beneficial effect of this beverage on inflammation. Furthermore, these results are in total agreement with the decreased inflammatory markers and reduced redox state observed in the serum of these rats. These findings suggest that XN is able to affect adipose tissue homeostasis, increasing adipocyte hyperplasia and reducing adipocyte hypertrophy, probably by affecting inflammatory and vascular components. Nevertheless, definitely this assumption deserves further investigation.

In summary, polyphenols are involved in complex signaling networks between many cell types, including inflammatory, endothelial, and adipocyte cells. The present study revealed that chronic ingestion of SB and XN-supplemented stout beer are able to control the complex interactions between inflammation and angiogenic processes in skin wound healing, both locally and systemically, resulting in improved wound healing resolution. These effects suggest that this polyphenol may exert beneficial effect as a nutritional supplement.

The interest in natural compounds, such as the polyphenols that are useful for disease prevention or treatment is increasing. Nevertheless, concern about potential toxic effects associated to different doses, and individual metabolism, must be taken into account before their implementation as food additives and potential therapeutic agents.

\section{ACKNOWLEDGMENTS}

The authors thank Paulo Magalhães for the production of xanthohumol and suggestions regarding beer supplementation. This study was partially funded by FCT (SFRM/BD/41888/2007 and PTDC/SAU-OSM/102083/2008 and PEst-OE/SAU/UI0038/2011); iBeSa (Institute for Beverages and Health, Portugal; P10-08).

\section{REFERENCES}

Albini A, Dell'Eva R, Vene R, Ferrari N, Buhler DR, Noonan DM, Fassina G. 2006. Mechanisms of the antiangiogenic activity by the hop flavonoid xanthohumol: NF-kappaB and Akt as targets. FASEB J 20:527-529.

Altavilla D, Saitta A, Cucinotta D, Galeano M, Deodato B, Colonna M, Torre V, Russo G, Sardella A, Urna G, Campo GM, Cavallari V, Squadrito G, Squadrito F. 2001. Inhibition of lipid peroxidation restores impaired vascular endothelial growth factor expression and stimulates wound healing and angiogenesis in the genetically diabetic mouse. Diabetes 50:667-674.

Assuncao M, Santos-Marques MJ, Monteiro R, Azevedo I, Andrade JP, Carvalho F, Martins MJ. 2009. Red wine protects against ethanol-induced oxidative stress in rat liver. J Agric Food Chem 57:6066-6073.

Biesalski HK. 2007. Polyphenols and inflammation: Basic interactions. Curr Opin Clin Nutr Metab Care 10:724-728.

Bolca S, Li J, Nikolic D, Roche N, Blondeel P, Possemiers S, De Keukeleire D, Bracke M, Heyerick A, van Breemen RB, Depypere H. 2010. Disposition of hop prenylflavonoids in human breast tissue. Mol Nutr Food Res 54(Suppl 2): S284-S294.

Bora PS, Kaliappan S, Xu Q, Kumar S, Wang Y, Kaplan HJ, Bora NS. 2006. Alcohol linked to enhanced angiogenesis in rat model of choroidal neovascularization. FEBS J 273:1403-1414.

Cho YC, Kim HJ, Kim YJ, Lee KY, Choi HJ, Lee IS, Kang BY. 2008. Differential anti-inflammatory pathway by xanthohumol in IFN-gamma and LPSactivated macrophages. Int Immunopharmacol 8:567-573.

Chung AS, Lee J, Ferrara N. 2010. Targeting the tumour vasculature: Insights from physiological angiogenesis. Nat Rev Cancer 10:505-514.

Costa C, Incio J, Soares R. 2007. Angiogenesis and chronic inflammation: Cause or consequence? Angiogenesis 10:149-166. 
Dorn C, Bataille F, Gaebele E, Heilmann J, Hellerbrand C. 2010. Xanthohumol feeding does not impair organ function and homoeostasis in mice. Food Chem Toxicol 48:1890-1897.

Eming SA, Brachvogel B, Odorisio T, Koch M. 2007. Regulation of angiogenesis: Wound healing as a model. Prog Histochem Cytochem 42:115-170.

Folkman J. 2007. Angiogenesis: An organizing principle for drug discovery? Nat Rev Drug Discov 6:273-286.

Fraga CG, Galleano M, Verstraeten SV, Oteiza PI. 2010. Basic biochemical mechanisms behind the health benefits of polyphenols. Mol Aspects Med 31:435-445.

Friedewald WT, Levy RI, Fredrickson DS. 1972. Estimation of the concentration of low-density lipoprotein cholesterol in plasma, without use of the preparative ultracentrifuge. Clin Chem 18:499-502.

Gasowski B, Leontowicz M, Leontowicz H, Katrich E, Lojek A, Ciz M, Trakhtenberg S, Gorinstein S. 2004. The influence of beer with different antioxidant potential on plasma lipids, plasma antioxidant capacity, and bile excretion of rats fed cholesterol-containing and cholesterol-free diets. J Nutr Biochem 15:527-533.

Gerhauser C. 2005. Beer constituents as potential cancer chemopreventive agents. Eur J Cancer 41:1941-1954.

Gollisch KS, Brandauer J, Jessen N, Toyoda T, Nayer A, Hirshman MF, Goodyear LJ. 2009. Effects of exercise training on subcutaneous and visceral adipose tissue in normal- and high-fat diet-fed rats. Am J Physiol Endocrinol Metab 297:E495-E504.

Gu JW, Bailey AP, Sartin A, Makey I, Brady AL. 2005. Ethanol stimulates tumor progression and expression of vascular endothelial growth factor in chick embryos. Cancer 103:422-431.

Guerreiro S, Monteiro R, Martins MJ, Calhau C, Azevedo I, Soares R. 2007. Distinct modulation of alkaline phosphatase isoenzymes by 17 beta-estradiol and xanthohumol in breast cancer MCF-7 cells. Clin Biochem 40:268-273.

Holst B, Williamson G. 2008. Nutrients and phytochemicals: From bioavailability to bioefficacy beyond antioxidants. Curr Opin Biotechnol 19:73-82.

Jones DP. 2006. Redefining oxidative stress. Antioxid Redox Signal 8:18651879.

Kagawa S, Matsuo A, Yagi Y, Ikematsu K, Tsuda R, Nakasono I. 2009. The time-course analysis of gene expression during wound healing in mouse skin. Leg Med (Tokyo) 11:70-75.

Kawai Y, Tanaka H, Murota K, Naito M, Terao J. 2008. (-)-Epicatechin gallate accumulates in foamy macrophages in human atherosclerotic aorta: implication in the anti-atherosclerotic actions of tea catechins. Biochem Biophys Res Commun 374:527-532.

Loots MA, Lamme EN, Zeegelaar J, Mekkes JR, Bos JD, Middelkoop E. 1998. Differences in cellular infiltrate and extracellular matrix of chronic diabetic and venous ulcers versus acute wounds. J Invest Dermatol 111:850-857.

Magalhaes PJ, Carvalho DO, Cruz JM, Guido LF, Barros AA. 2009. Fundamentals and health benefits of xanthohumol, a natural product derived from hops and beer. Nat Prod Commun 4:591-610.

Mahdavian Delavary B, van der Veer WM, van Egmond M, Niessen FB, Beelen RH. 2011. Macrophages in skin injury and repair. Immunobiology 216:753-762.

Monteiro R. 2009. Chronic inflammation in the metabolic syndrome: Emphasis on adipose tissue. In: C, SRaC editor. Oxidative stress, inflammation and angiogenesis in the metabolic syndrome. Milton Keynes, UK: Springer Science. Hardcover, pp 65-83.

Monteiro R, de Castro PM, Calhau C, Azevedo I. 2006. Adipocyte size and liability to cell death. Obes Surg 16:804-806.

Monteiro R, Calhau C, Silva A0, Pinheiro-Silva S, Guerreiro S, Gartner F, Azevedo I, Soares R. 2008. Xanthohumol inhibits inflammatory factor production and angiogenesis in breast cancer xenografts. J Cell Biochem 104:1699-1707.
Morrow D, Cullen JP, Cahill PA, Redmond EM. 2008. Ethanol stimulates endothelial cell angiogenic activity via a Notch- and angiopoietin-1dependent pathway. Cardiovasc Res 79:313-321.

Nascimento AP, Costa AM. 2006. Overweight induced by high-fat diet delays rat cutaneous wound healing. Br J Nutr 96:1069-1077.

Negrao R, Costa R, Duarte D, Taveira Gomes T, Mendanha M, Moura L, Vasques L, Azevedo I, Soares R. 2010. Angiogenesis and inflammation signaling are targets of beer polyphenols on vascular cells. J Cell Biochem 111:1270-1279.

Nozawa H. 2005. Xanthohumol, the chalcone from beer hops (Humulus lupulus L.), is the ligand for farnesoid $\mathrm{X}$ receptor and ameliorates lipid and glucose metabolism in KK-A(y) mice. Biochem Biophys Res Commun 336:754-761.

Oak MH, El Bedoui J, Schini-Kerth VB. 2005. Antiangiogenic properties of natural polyphenols from red wine and green tea. J Nutr Biochem 16:1-8.

Pond CM. 2003. Paracrine interactions of mammalian adipose tissue. J Exp Zool A Comp Exp Biol 295:99-110.

Qiao L, Lu SL, Dong JY, Song F. 2011. Abnormal regulation of neovascularisation in deep partial thickness scalds in rats with diabetes mellitus. Burns 37:1015-1022.

Radek KA, Kovacs EJ, Gallo RL, DiPietro LA. 2008. Acute ethanol exposure disrupts VEGF receptor cell signaling in endothelial cells. Am J Physiol Heart Circ Physiol 295:H174-H184.

Reagan-Shaw S, Nihal M, Ahmad N. 2008. Dose translation from animal to human studies revisited. FASEB J 22:659-661.

Rodero MP, Khosrotehrani K. 2010. Skin wound healing modulation by macrophages. Int J Clin Exp Pathol 3:643-653.

Roig R, Cascon E, Arola L, Blade C, Salvado MJ. 1999. Moderate red wine consumption protects the rat against oxidation in vivo. Life Sci 64:15171524.

Shoab SS, Scurr JH, Coleridge-Smith PD. 1999. Plasma VEGF as a marker of therapy in patients with chronic venous disease treated with oral micronised flavonoid fraction - a pilot study. Eur J Vasc Endovasc Surg 18:334338.

Soares R, Azevedo I. 2007. Inhibition of S1P by polyphenols prevents inflammation and angiogenesis: NFkappaB, a downstream effector? Free Radic Biol Med 42:311.

Soares RCC. 2009. Oxidative stress, inflammation and angiogenesis in the metabolic syndrome. Milton Keynes, UK: Springer Science. Hardcover.

Stevens JF, Page JE. 2004. Xanthohumol and related prenylflavonoids from hops and beer: To your good health. Phytochemistry 65:13171330.

Stevenson DE, Hurst RD. 2007. Polyphenolic phytochemicals-just antioxidants or much more? Cell Mol Life Sci 64:2900-2916.

Strathmann J, Klimo K, Sauer SW, Okun JG, Prehn JH, Gerhauser C. 2010. Xanthohumol-induced transient superoxide anion radical formation triggers cancer cells into apoptosis via a mitochondria-mediated mechanism. FASEB J 24:2938-2950.

Tan W, Bailey AP, Shparago M, Busby B, Covington J, Johnson JW, Young E, $\mathrm{Gu}$ JW. 2007. Chronic alcohol consumption stimulates VEGF expression, tumor angiogenesis and progression of melanoma in mice. Cancer Biol Ther 6:1211-1217.

Tosetti F, Noonan DM, Albini A. 2009. Metabolic regulation and redox activity as mechanisms for angioprevention by dietary phytochemicals. Int J Cancer 125:1997-2003.

Winkelmann LSM. 2004. Highly innovative products rich in xanthohumol. Brauwelt Int 5:300-301.

Xan P. 2011. http://xan.com/en/produkte/xan-wellness SCHULTZEPLUS, Germany. 